\title{
Development and Testing of Gluten-Free Pasta Based on Rice, Quinoa and Amaranth Flours
}

\author{
Sarah Makdoud ${ }^{1} \&$ Kurt A. Rosentrater ${ }^{1}$ \\ ${ }^{1}$ Agricultural and Biosystems Engineering, Food Science and Human Nutrition, Iowa State University, United \\ States \\ Correspondence: Kurt A. Rosentrater, Agricultural and Biosystems Engineering, Food Science and Human \\ Nutrition, Iowa State University, United States. E-mail: karosent@iastate.edu
}

Received: January 13, 2017 Accepted: June 16, $2017 \quad$ Online Published: June 26, 2017

doi:10.5539/jfr.v6n4p91

URL: https://doi.org/10.5539/jfr.v6n4p91

\begin{abstract}
The goal of this study was to make high quality gluten-free pasta using amaranth, quinoa and rice flours, water and eggs using extrusion processing, and to compare these with gluten-free pasta already commercialized. The difficulty was to reproduce the texture provided by the gluten network without using gluten. To do that, an experimental design was created in order to make samples with different quantities of each grain, egg whites and water. Samples were manufactured and various tests (e.g., color analysis, water activity, cooking loss, texture, etc.) were carried out in order to find the best formulation, namely the formulation which was closest to Barilla or Andean dream gluten-free commercial pasta. With Rcommander software, results were analyzed and it was determined that the best pasta formulation was $10 \%$ amaranth flour, $40 \%$ quinoa flour, and $50 \%$ rice flour, with $18 \%$ eggs whites and $39 \%$ water. This optimal formulation was manufactured and subjected to sensory analysis with other commercial samples (Barilla, Andean Dream). Statistical analyses were conducted and it was shown that, even though this formulation did not quite achieve Barilla or Andean Dream pastas quality, it approached closely in some parameters. Indeed, $80 \%$ of consumers did not refuse to eat this pasta again, and with addition of tomato sauce, no differences were seen between the spaghettis. However, individual sample analysis did indicate that consumers did not appreciate the formulation's sticky texture, thus this parameter would have to be reworked to achieve higher quality.
\end{abstract}

Keywords: celiac disease, gluten-free, quinoa, amaranth, rice, pasta, extrusion

\section{Introduction}

Celiac disease (CD), also known as celiac sprue and gluten sensitive enteropathy, is a permanent intolerance to gluten and one of the most frequent food intolerance worldwide. It may be defined as an inflammatory disease of the upper small intestine in genetically susceptible individuals, in both children and adults, triggered by ingestion of wheat, rye, barley, and possibly oat products. Indeed, the precipitating factor of $\mathrm{CD}$ are the storage proteins of these cereals, found in the triticeae tribe of grains and widely called gluten, which are harmful for the sensitive consumers (Wieser and Koelher, 2007).

For these people, eating gluten causes the villi of the intestine to atrophy, which prevents food from being absorbed and produces an inflammatory reaction (Broz and Horn, 2007).

Many different symptoms are associated with $\mathrm{CD}$, which can be divided into intestinal features (chronic diarrhea, vomiting, abdominal distension, etc.) and into the results of malabsorption (deficiencies of vitamins and minerals, loss of weight, etc.). Currently, the only effective treatment for CD is the strict lifelong renunciation of gluten containing foods. Unfortunately, most common foods and beverages, such as bread, biscuits, beer, pizza and pasta, are made from cereals containing gluten such as wheat. Wheat contains two proteins, glutenin and gliadin, which during mixing and kneading develop into gluten. Gluten is responsible for the protein-starch interaction that provides specific viscoelastic properties in products.

Since the discovery of Dicke (1950) that the ingestion of wheat was responsible for the symptoms of CD, numerous reviews appeared in order to meet the demand for gluten-free products such as pasta. Indeed, pasta is a highly convenient food product, consumed all over the world. The term usually refers to unleavened extruded wheat dough, composed simply of flour and water, sometimes egg. Pasta provides significant quantities of 
complex carbohydrates, proteins, B-vitamins, and iron and is low in sodium, amino acids, and total fat. However, a significant part of the human population cannot tolerate gluten, hence, there is a high demand for gluten-free pasta. Furthermore, there is also a growing segment of the population choosing to follow gluten-free diet for nonmedical reasons. These people may have family or friends with gluten intolerance or they may simply feel better on a gluten-free diet. Indeed, switching from refined wheat products to nutritionally more valuable grains could bring benefits regarding health and well-being (Hager et al., 2012).

Thus, the target for development is to develop gluten-free pasta suitable for the CD patient with a taste and texture similar to those of pastas made with whole wheat flour. That is a big challenge for food research and development, because the network forming ability of gluten needs to be substituted by other means, in order to achieve products with satisfying quality (Schoenlechner et al., 2010).

Though wheat, rye, barley and possibly oats are harmful, corn, rice, amaranth, quinoa, buckwheat and teff are not and can be used in gluten-free pasta formulation. Furthermore, these ancient grains have nutrition, antioxidants, and textural qualities suitable for functional foods.

Amaranth (Amaranthus caudatus) and Quinoa (Chenopodium quinoa) contain about thirty percent more protein than cereals such as rice, sorghum and rye. They are a good source of the essential amino acid, lysine, which is low in other grains, and dietary minerals including calcium, magnesium, and phosphorus. Quinoa, also called super food because of its remarkable nutritional value, contains antioxidant phytonutrients (polyphenols and phytosterols) and flavonoid in concentrated amounts with possible nutraceutical benefits. Moreover, quinoa starch has useful physicochemical properties, such as viscosity and freeze stability (Inglett et al., 2015). Because these grains have unique characteristics, studies focused on the manufacture and characterization of gluten-free pastas have been conducted. They evaluated Quinoa and Amaranth's pasting properties, water holding capacities, phenolic contents, and antioxidant activities. In each case, the spaghetti samples were manufactured by means of a pilot plant equipped with an extruder and a spaghetti nozzle, for the production of fresh-extruded spaghetti, and a dryer for the production of the dry spaghetti. Different type of grains and flour were used to prepare the dough. Some samples were manufactured with a mixture of pre-gelatinized flour and conventional flour, whereas others samples were only manufactured with conventional flour. Pre-gelatinization is done using a steam cooker, where a quantity of water was mixed with another quantity of flour and heated for about $1 \mathrm{~h}$ and then cooled. Once pasta made, samples were taken for physicochemical measurements such as dough rheological properties, carotenoid determination, chemical determination, spaghetti cooking quality (optimal cooking time, cooking loss, swelling index and water absorption), texture, determination of gelatinization degree, in vitro digestion, sensory analysis, etc.) (Padalino et al., 2012).

Studies show that there is an unbalanced intake of carbohydrates, protein, and fat, as well as limited intake of certain essential nutrients in celiac subjects compared to a control group of people on a normal diet. Indeed, commercial gluten-free pasta often shows significantly lower protein contents compared to wheat-containing counterparts. Hence, the utilization Amaranth and Quinoa is beneficial as they contain higher amounts of protein than many other flours, as vegetable flour or wheat flour. Moreover, apart from the utilization of high-quality raw materials, enrichment with additional protein ingredients is another approach to improve the nutritional value but also the texture of gluten-free products. An obvious ingredient to increase the protein content of pasta is egg. Eggs are traditionally used in pasta mainly to achieve flavor effects, but can also aid structure formation. Egg proteins facilitate the formation of a tighter protein network, yielding a harder product, both before and after cooking. In addition, the tighter protein network reduces penetration by water and hence starch granule swelling during cooking.

Gluten-free dough is often more fragile, less elastic and more susceptible to overworking; thus, the production of pasta based solely on gluten-free flours has largely been unsuccessful. Several publications report that cooking loss is increased for gluten-free products, due to the absence or interruption of the gluten network Indeed, a single ingredient that will replace gluten does not exist. This is in agreement with previous authors who also found that additional structuring agents are necessary to obtain extrudable dough. Chillo et al. (2007) were not successful in the production of oat pasta unless carboxymethylcellulose and pre-gelatinized starch were added. Moreover, Sabanis and Tzia (2011) showed that a major role in the formation of a tight protein network is played by ovalbumin, the main protein of albumin.

According to Engleson and Atwell (2008), the common approach to improve the texture of gluten-free product is to assemble a mixture of starches, hydrocolloids, fibers and dairy ingredients to replace all the functionalities of pasta with gluten. In addition to proteins, others structuring agents can be used like carboxymethylcellulose, transglutaminase and pre-gelatinized starch to mimic the viscoelastic properties of gluten in gluten-free pasta. 
Also, the fatty nature of emulsifiers enables them to act as a lubricant in the extrusion process, resulting in less nozzle wear and tear and thus making production easier. Hager et al. (2012) found that mono- and diglycerides of fatty acids form complexes with amylose, thereby preventing the passage of starch into the cooking water, reducing cooking loss and stickiness.

More specific research was carried out to study the effect of three non-grasses cereals, amaranth, quinoa and buckwheat, in gluten-free pasta production. The results demonstrated that pasta produced from amaranth decreased texture firmness, cooking time and cooking tolerance, while pasta from quinoa were better agglutinated but showed increased cooking loss. In buckwheat pasta the least negative effects were observed.

By combination of all three raw materials to one flour blend (60\% buckwheat, $20 \%$ amaranth and $20 \%$ quinoa), dough matrix and nutritional properties were improved. The quality of the product was more improved with addition of xanthan, egg or emulsifier. In order to replace the missing gluten in amaranth, quinoa and buckwheat flour a further aim of investigation was the addition of different protein isolates. The isolates selected were egg white powder, soy protein isolate and casein. The egg addition had positive effects on gluten-free pasta quality: higher texture firmness and lower cooking loss (except for buckwheat pasta). Cooking time was reduced in the pasta with soy protein and casein added pasta, demonstrating that the dough matrix was not strong enough to prevent the pasta from disintegration. Dough moisture is also recognized to have a major influence on pasta quality. High dough moisture toughened the dough, which adhered to the screw of the pasta machine and the produced pasta were very sticky, disintegrated during boiling and therefore showed very low texture firmness. Too low dough moisture resulted in noodles, which showed surface cracks. Additionally, dough moisture content had a significant effect on cooking loss, which was minimized with lower moisture content. After several trials, optimum dough moisture content to increase texture firmness and minimize cooking loss was determined to be $30 \%$. Then, addition of emulsifier (DATEM and DMG) in gluten-free pasta was studying. Generally, according to the food additive legislation, it is not allowed to add emulsifiers to dry pasta, but an exception can be made for gluten-free pasta. Results show that only the addition of DMG $(1,2 \%)$ improved dough matrix in all three pastas: texture firmness and cooking weight were increased and cooking loss decreased.

In sum, by addition of an increased amount of egg white powder (up to 6\% of flour) and the emulsifier DMG ( $1.2 \%$ of flour) at optimum dough moisture $(30 \%)$, the cooking quality parameter for all produced pasta were within a satisfying range. Cooking time could be defined to $8 \mathrm{~min}$ for all pasta, which corresponds to the average cooking time for wheat pasta. Furthermore, pastas were much better agglutinated, showed good texture firmness and low cooking loss.

However, compared to wheat pasta, the gluten-free pasta produced from non-grasses differs in terms of color, elasticity and sensory properties. Thus, in order to optimize these parameters, still more research will be necessary (Schoenlechner et al., 2010).

Thus the goal of this research was to make high quality gluten-free pasta using a mixture of grains (amaranth, quinoa, and rice), water and egg whites. To do this, an experimental design was created and different samples were made with a Kitchen Aid mixer. Several tests were carried out in order to find the optimal recipe using a suitable proportion of water, eggs and flour. After that, a sensory analysis and consumer acceptance were performed on the best formulation and compared to Barilla and Andean Dream gluten-free pasta, which were controls in this study.

\section{Materials and Methods}

\subsection{Raw Materials}

Amaranth grains were provided by Nutricity LLC (Scottsdale, Arizona, United States). Rice flour (Bob's Red Mill) and quinoa grains (Full Circle) were obtained at a local market (Hyvee, Des Moines, Iowa, United States). All trial pastas were compared with Barilla and Andean dream gluten-free pasta also found in the same local market.

Grains were milled into particles of diameter $0.7 \mathrm{~mm}$ or less, using a grinding machine (Magic Bullet, MB 1001)

\subsection{Pasta Production}

\subsubsection{Pasta Dough Formulation}

The doughs were made by combining flours, eggs and water. The addition of water is the most critical part of the dough manufacture. Actually, if the moisture content is too high, the dough will be too sticky to be extrude. On the contrary, if the moisture content is too low, it will be difficult to knead it and it will be impossible to extrude. Also, according to Schoenlechner et al. (2010), the dough moisture is an important parameter because it has an 
influence on pasta quality; if the dough moisture is too high, the pasta will be too sticky and they will disintegrate during cooking.

\begin{tabular}{|c|c|c|c|c|}
\hline $\mathrm{N}$ & $\mathrm{X} 1$ & $\mathrm{X} 2$ & $\mathrm{X} 3$ & $\mathrm{X} 4$ \\
\hline 1 & 0 & 0 & 0 & 0 \\
\hline 2 & 1 & 0 & 0 & 0 \\
\hline 3 & 0,5 & 0,866 & 0 & 0 \\
\hline 4 & 0,5 & 0,2887 & 0,8165 & 0 \\
\hline 5 & 0,5 & 0,2887 & 0,2041 & 0,7906 \\
\hline 6 & -1 & 0 & 0 & 0 \\
\hline 7 & $-0,5$ & $-0,866$ & 0 & 0 \\
\hline 8 & $-0,5$ & $-0,2887$ & $-0,8165$ & 0 \\
\hline 9 & $-0,5$ & $-0,2887$ & $-0,2041$ & $-0,7906$ \\
\hline 10 & 0,5 & $-0,866$ & 0 & 0 \\
\hline 11 & 0,5 & $-0,2887$ & $-0,8165$ & 0 \\
\hline 12 & 0,5 & $-0,2887$ & $-0,2041$ & $-0,7906$ \\
\hline 13 & $-0,5$ & 0,866 & 0 & 0 \\
\hline 14 & 0 & 0,5774 & $-0,8165$ & 0 \\
\hline 15 & 0 & 0,5774 & $-0,2041$ & $-0,7906$ \\
\hline 16 & $-0,5$ & 0,2887 & 0,8165 & 0 \\
\hline 17 & 0 & $-0,5774$ & 0,8165 & 0 \\
\hline 18 & 0 & 0 & 0,6124 & $-0,7906$ \\
\hline 19 & $-0,5$ & 0,25887 & 0,2041 & 0,7606 \\
\hline 20 & 0 & $-0,5774$ & 0,2041 & 0,7606 \\
\hline 21 & 0 & 0 & $-0,6124$ & 0,7906 \\
\hline
\end{tabular}
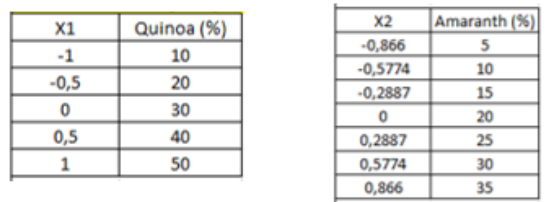

\begin{tabular}{|c|c|}
\hline$X 3$ & White eggs (\%) \\
\hline$-0,8165$ & 10 \\
\hline$-0,6124$ & 11 \\
\hline$-0,2041$ & 13 \\
\hline 0 & 14 \\
\hline 0,2041 & 15 \\
\hline 0,6124 & 17 \\
\hline 0,8165 & 18 \\
\hline
\end{tabular}

\begin{tabular}{|c|c|}
\hline $\mathrm{X} 4$ & Moisture Content \\
\hline$-0,7906$ & 33 \\
\hline 0 & 36 \\
\hline 0,7606 & 39 \\
\hline
\end{tabular}

Figure 1. Experimental matrix using a Doehlert experimental design

In order to find the best recipe, different samples were made according to a formal experimental design. We choose to use a Doehlert experimental design with 4 factors: quantity of amaranth, quinoa, eggs and water. Rice quantity was adjusted with the others. Thus, 21 samples were prepared. The experimental design matrix is detailed in Figure 1.

To make pasta dough, flours were mixed together and adequate amounts of water and egg whites were slowly added during mixing using a laboratory scale mixer (Kitchen Aid KSM75WH) with a speed of 2 for a duration of $5 \mathrm{~min}$. Then, the dough was kneaded by hand during $10 \mathrm{~min}$ and stored in a refrigerator for $15 \mathrm{~min}$. 

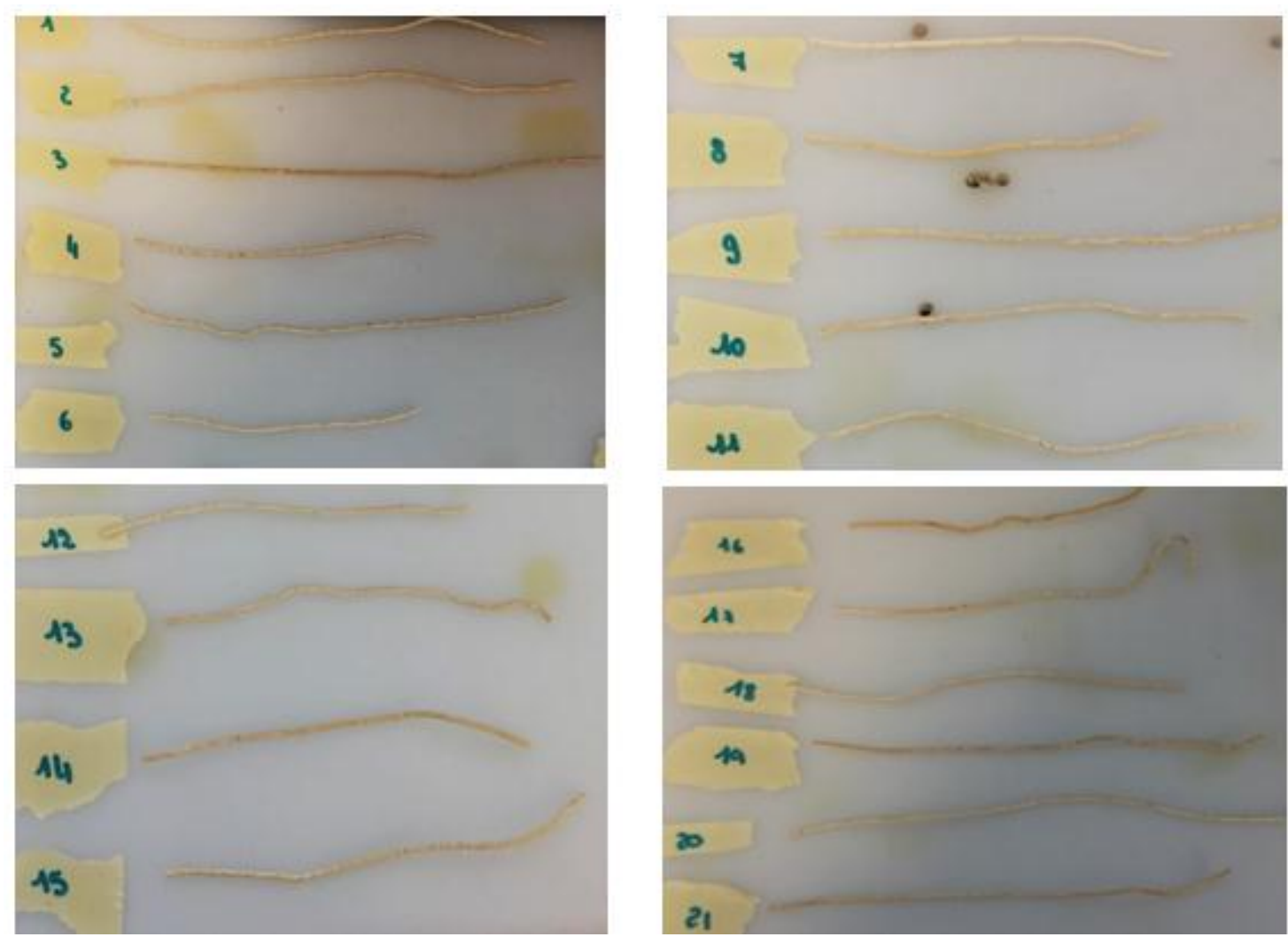

Figure 2. Pictures of all pasta samples (experimental treatments are detailed in Figure 1)

\subsubsection{Pasta Manufacture}

After $15 \mathrm{~min}$ in the refrigerator, the extrusion processing was performing using a Stand-Mixer Pasta-Extruder Attachment (Kitchen Aid KPEXTA) with a speed of 4. The diameter of the holes of the disc die was $\approx 1.65 \mathrm{~mm}$. Extruded spaghettis were immediately manually separated and air-dried for $24 \mathrm{~h}$ at ambient temperature (around $25^{\circ} \mathrm{C}$ ), then they were stored in airtight bags. Pictures of all trial pastas are presented in Figure 2.

\subsection{Physical Analyses of Pasta}

\subsubsection{Moisture Content}

Moisture content was determined according to the AACC method 44-19 (AACC, 2000). $2 \mathrm{~g}$ dried spaghettis were put into the oven (Heratherm General Protocol Ovens, ThermoFisher Scientific, Waltham, Massachusetts, United States) at $135^{\circ} \mathrm{C}$ during $2 \mathrm{~h}$. The mass difference between the initial and final weights gives the moisture content of samples:

$$
M C(\%)=\frac{D P W-O P W}{D P W} \times 100
$$

$\mathrm{DPW}=$ dried pasta weight $(\mathrm{g}) ; \mathrm{OPW}=$ original $($ wet $)$ pasta weight $(\mathrm{g})$

\subsubsection{Unit Density}

According to Rosentrater et al. (2005), unit density was determined on dried spaghettis as the ratio of the mass (m) to the volume (V). The volume was calculated by measuring the length (L) and the diameter (D) of the sample thanks to the Traceable Electronic Digital Caliper (Fisher Scientific, Pittsburg, Pennsylvania 15275, United States). Spaghetti were assumed to be a cylinder shape, so the following formula can be used:

$$
V=\pi \times \frac{D^{2}}{4} \times L
$$

Unit density (UD) was expressed in $\mathrm{kg} / \mathrm{m}^{3}$. 


$$
U D=\frac{m}{V}
$$

\subsubsection{Color Analysis}

Uncooked spaghetti color was measured using the Chroma Meter CR-410 colorimeter (Konica Minolta Optics, Inc. Chroma meter, Ramsey, New Jersey, USA) equipped with a xenon lamp. Samples were put in a petri dish and the measure was made by direct contact between the sensing head of the colorimeter and the samples. Spaghettis were characterized by three parameters: L* (lightness, scale of 100; 0 matches with black and 100 with white), $\mathrm{a}^{*}$ (greenness/redness) and $\mathrm{b}^{*}$ (blueness/yellowness). The colorimetric difference $\Delta \mathrm{E}$ between two samples can be estimated with the following formula:

$$
\Delta \mathrm{E}=\sqrt{(\Delta \mathrm{L} *)^{2}+(\Delta \mathrm{a} *)^{2}+(\Delta \mathrm{b} *)^{2}}
$$

If the colorimetric difference is lower than 2, then an unexperienced observer cannot visibly see the difference between two samples in terms of color (Mokryzcki and Tatol, 2011).

\subsubsection{Water Activity}

Water activity was measured at room temperature using a calibrated water activity meter (AquaLab, series 3TE, model 0800753, Decagon Devices, Inc., Pullman, Washington, USA). The bowl of the water activity meter was filled with cut samples and placed in the measuring chamber of the instrument for measuring the water activity.

\subsubsection{Optimal Cooking Time}

The optimal cooking time (OCT) was determined according to the AACC Approved Method 66-50, where 5-g dried spaghetti samples were boiled in $200 \mathrm{~mL}$ of distilled water. Each $30 \mathrm{sec}$, a spaghetti was removed from boiling water and squeezed between two pieces of Plexiglas. Spaghettis were considered cooked when the center core disappeared.

\subsubsection{Water Absorption and Cooking Loss}

Water absorption (WA) and cooking loss (CL) were determined according to the AACC Approved Method 66-50. $10 \mathrm{~g}$ dried spaghettis samples were pre-weighed and boiled in $300 \mathrm{~mL}$ of water during the cooking time previously determined. Then, spaghettis were removed and weighed: the weight difference before and after cooking was used to calculate the water absorption.

$$
\begin{gathered}
W A(\%)=\frac{\mathrm{CPW}-\mathrm{DPW}}{D P W} * 100 \\
\mathrm{CPW}=\text { cooked (wet) pasta weight }(\mathrm{g}) \\
\mathrm{CPW}=\text { dried pasta weight }(\mathrm{g})
\end{gathered}
$$

Solids particles that diffuse from pastas into the cooking water are known as CL. CL was measured by putting cooked pasta in an oven at $50^{\circ} \mathrm{C}$ for $48 \mathrm{~h}$ (using the same units as described previously):

$$
C L(\%)=\frac{D P W-O P W}{D P W} \times 100
$$

\subsubsection{Texture Analysis}

Dried pasta texture was measured using three replicate pastas for each treatment with a texture analyzer (Autograph AGS-J, SHIMADZU). The test included a three-point bending fixture, which measured the force required to break each pasta sample. For each measurement, a single strand of pasta of about $3 \mathrm{~cm}$ in length was placed in the center of the fixture (the gap between the supports was $24 \mathrm{~mm}$ ). Then, the test probe moved with a speed of $1 \mathrm{~mm} / \mathrm{min}$ until breakage occurred. The probe movement caused deformation of the pasta sample until the sample fractured. The texture analyzer software recorded force and stroke data, with which the stress-strain relationship could be obtained. A typical curve is shown in Figure 3. Stress and strain were calculated according to the formulae:

$$
\operatorname{Stress}\left(N / \mathrm{mm}^{2}\right)=\frac{F * L}{\pi r^{3}}
$$


$\mathrm{F}=$ force $(\mathrm{N}) ; \mathrm{L}=$ gap between the supports; $\mathrm{r}=$ spaghetti radius $(\mathrm{mm})$

$$
\begin{aligned}
\text { Strain } & =\frac{6 * D * d}{L^{2}} \\
\mathrm{D}=\text { course }(\mathrm{mm}) ; \mathrm{d} & =\text { spaghetti diameter }(\mathrm{mm})
\end{aligned}
$$

The stress-strain relationship (Figure 3) during the matrix compression is divided into three distinct regions. The first involves elastic deformation of the intact structure. The second (A) comprises at break and irreversible structural collapse. Finally, the compression of the material completes the cycle (fracture point) (Gibson and Ashby, 1988).

From this curve, Young's modulus (calculation of the slope) and toughness (area under the curve) were calculated.

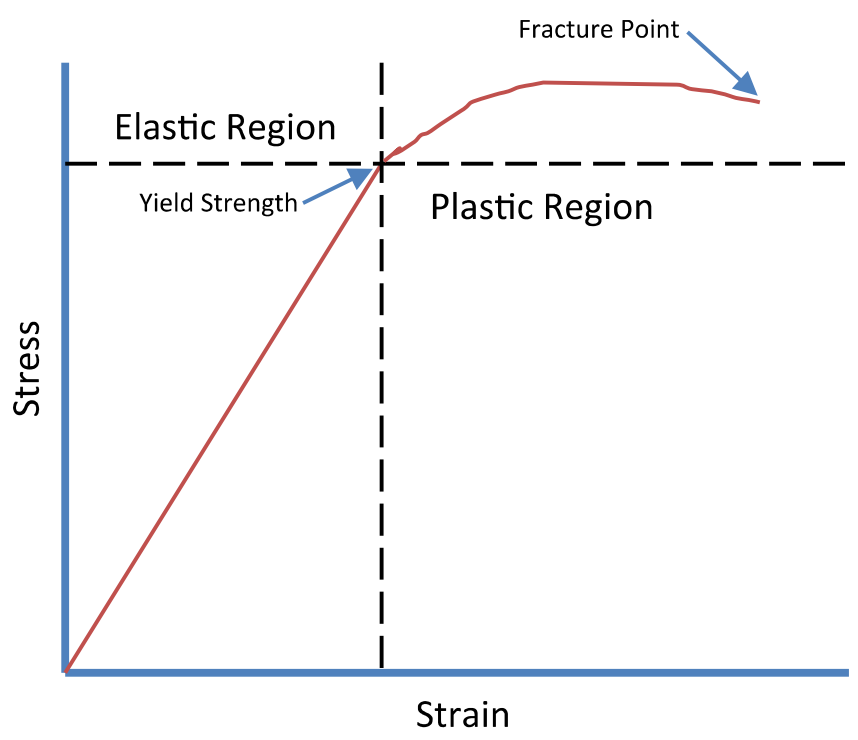

Figure 3. Typical Stress-Strain curve relationship

\subsection{Sensory Analysis}

The sensory test panel consisted of 10 untrained panelists ( 5 males and 5 females). Each of them was in an individual box to taste samples. A glass of water and a spittoon were at their disposal. Three different samples were tested: best formulation pastas made with the Kitchen Aid and gluten-free pastas from Andean Dream and Barilla. Spaghetti samples were cooked in tap water to optimum cooking time and served warm. The sensory analysis was divided into three different parts. The first part was a descriptive test of each spaghetti separately. It focused on different scale of perception, such as eyesight (color), odor, taste, texture, and overall acceptability. Descriptors were marked on scale of 5 . After that, consumers had to answer three questions: What did you like? What did you dislike? Will you be ready to consume this product again? Secondly, the three samples were distributed at the same time, and consumers had to choose their favorite formulation. To finish, the same test was reiterated with tomato salsa (Prego, Italian traditional) in pastas.

Results were compared using Microsoft Excel 2016 in order to find significant differences or similarities among samples. With the results of the ranking test, a Friedman test was realized. After classification of samples in ascending order, rank sum was calculated: the value given to each sample was relative to it's ranking. For example, if the sample A is found 7 times in first position, 2 times in second position and 1 time in third position, the sum of ranks is equal to $7 * 1+2 * 2+3=14$. From these data, the Friedman coefficient could be calculated with the following formula: 


$$
F=\left(\frac{12}{\mathcal{N} \cdot k \cdot(k+1)}\right) \cdot \sum R^{2}-(3 \cdot \mathcal{N} \cdot(k+1))
$$

$\mathrm{N}=$ number of panelists; $\mathrm{k}=$ number of samples; $\mathrm{R}=$ sum of ranks

To determine if the different pastas were perceived differently with or without sauce, the Friedman coefficient was compared with the critical value from the Friedman table (since $\mathrm{N}<14$ and $\mathrm{k}<6$ ). A level of significance of 0.05 was used for all statistical analyses.

\section{Results and Discussion}

All tests were analyzed both one by one, and all in one, via the experimental design.

\subsection{Moisture Content}

The moisture content is the percentage of water contained in dried pasta. Results of this measurement are illustrated in Figure 4.

In Figure 4 we can see that Barilla's MC was closer to our samples' MC, although it was higher in the experimental pasta. The moisture content depends on initial dough MC and it also depends on the drying process. Sample number 7 had the lowest MC even though our drying process was not as good as that in industry. According to Bustos et al. (2015), the pasta MC level had to be equal to or less than $12.5 \%$ after drying in order to avoid contamination by microorganisms. Here, all samples $\mathrm{MC}$ was under $12 \%$ so they were good concerning MC level.

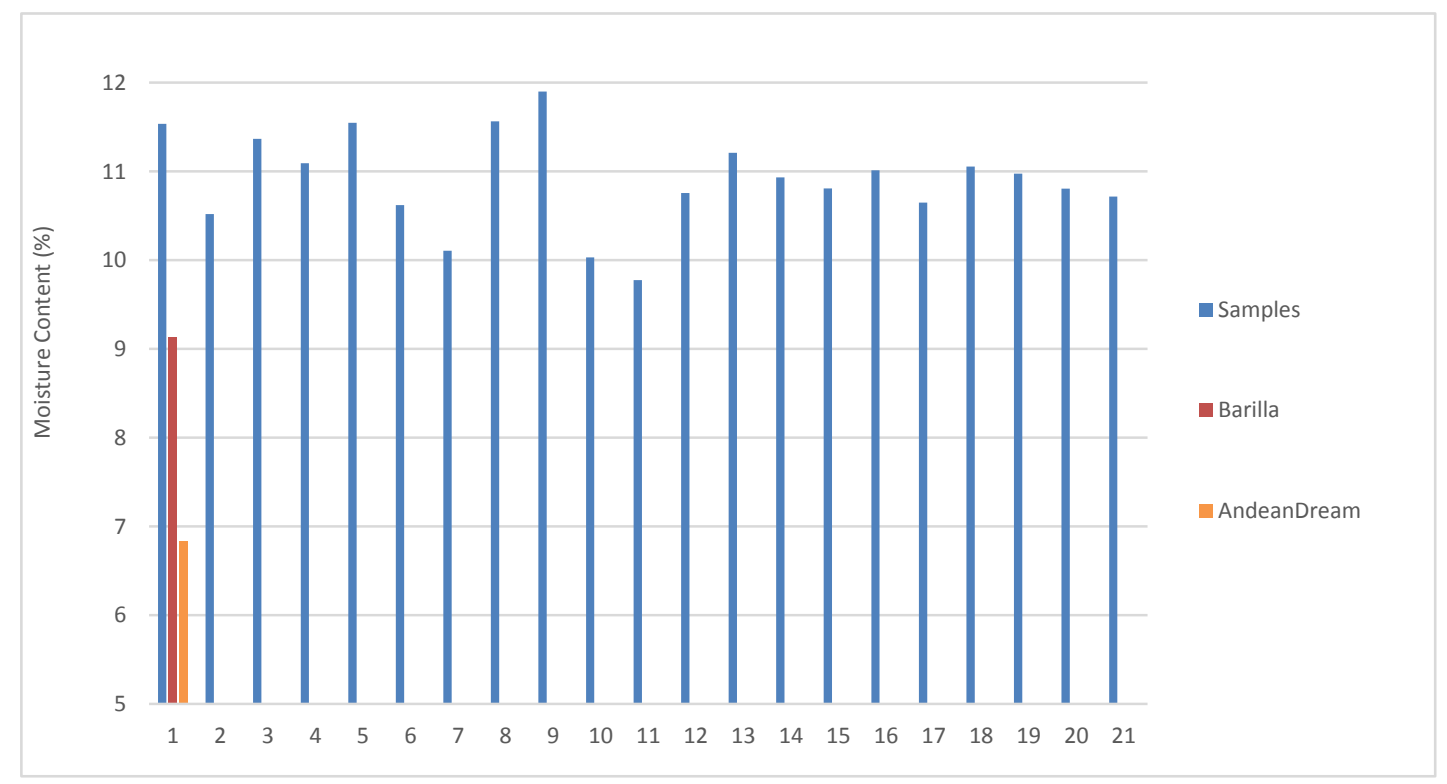

Figure 4. Moisture content of trial pastas and control pastas

Data analysis via Rcommander software showed that none of factors, including added water, had an effect on moisture content. The adjusted $\mathrm{R}^{2}$ was by $93 \%$ so the model seemed to be well suited. Leaving the samples dry in the open air and the amount of water added, thanks to the preliminary study, varying little (33 to 39\%); it is not surprising that water had no effect on the moisture content of the final product.

\subsection{Unit density}

Unit density measurement is used to understand the entrapped air in pastas. If there is a lot of air, spaghetti will have a low weight and a high volume, which means a low unit density. Results are shown below in Figure 5. 

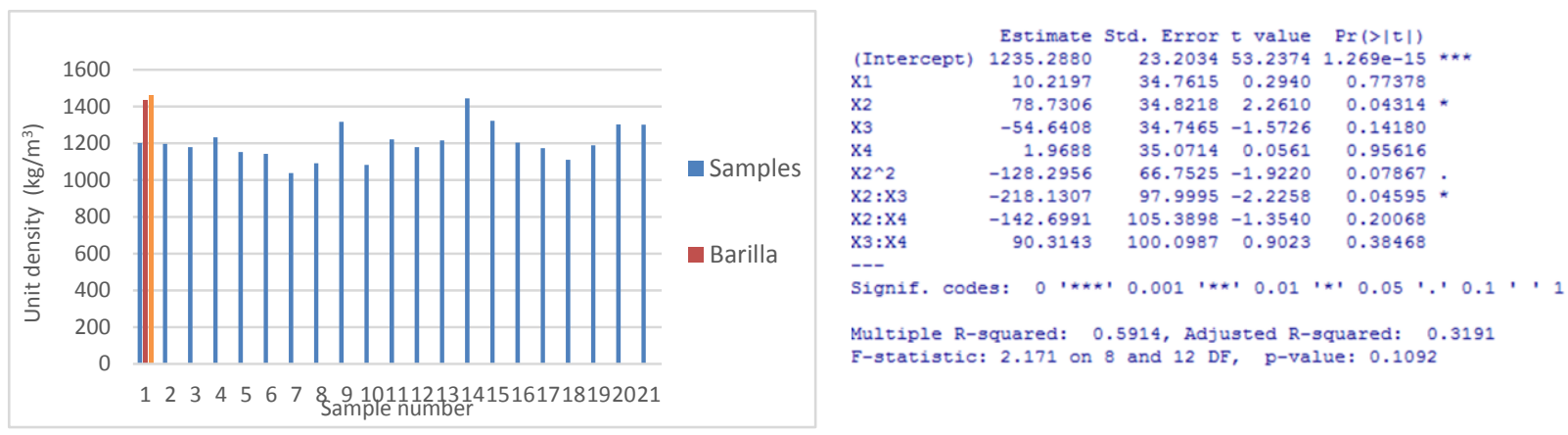

Figure 5. Unit density of trial pastas and control pastas; and Rcommander software results using the $\mathrm{FO}(\mathrm{X} 1, \mathrm{X} 2, \mathrm{X} 3, \mathrm{X} 4)+\mathrm{TWI}(\mathrm{X} 2, \mathrm{X} 3, \mathrm{X} 4)+\mathrm{PQ}(\mathrm{X} 2)$ design

According to Figure 5, unit density of the samples were lower than those of commercial pasta, but they were greater than $1000 \mathrm{~kg} / \mathrm{m}^{3}$, which means that the trial pastas will not float in water. So, it seems that particle bonding was good. Regarding the Rcommander results, even adjusting the best model, $\mathrm{R}^{2}$ remained low, with a value by $32 \%$. Based on these data, it appears that amaranth level and interaction with egg whites had an influence on the value of US, but the $\mathrm{R}^{2}$ was low. Although UD value can be influenced by ingredients, it also depends on the preparation process and above all, dough kneading. Indeed, air can be entrapped during this step. According to the previous figure, it seems that UD values were almost the same and suitable for all samples. Thus, this setting was acceptable and did not have to be improved.

\subsection{Color Analysis}

Colorimeter gives four results: $L^{*}, a^{*}, b^{*}$ and $\Delta$ E. All samples had a good lightness (Figure 6), $L^{*}$ was always higher than 60 but some were lighter than others. Results showed that an increase in lightness values $\left(\mathrm{L}^{*}\right)$ can be observed in samples containing more rice than quinoa and amaranth. According to Rosa et al. (2015), even if some consumers could accept dark pastas if they are healthier, lighter colored pastas most frequently have a better acceptance because consumers are accustomed to eat wheat pastas; thus it was important to add rice to our pasta in order to increase lightness.

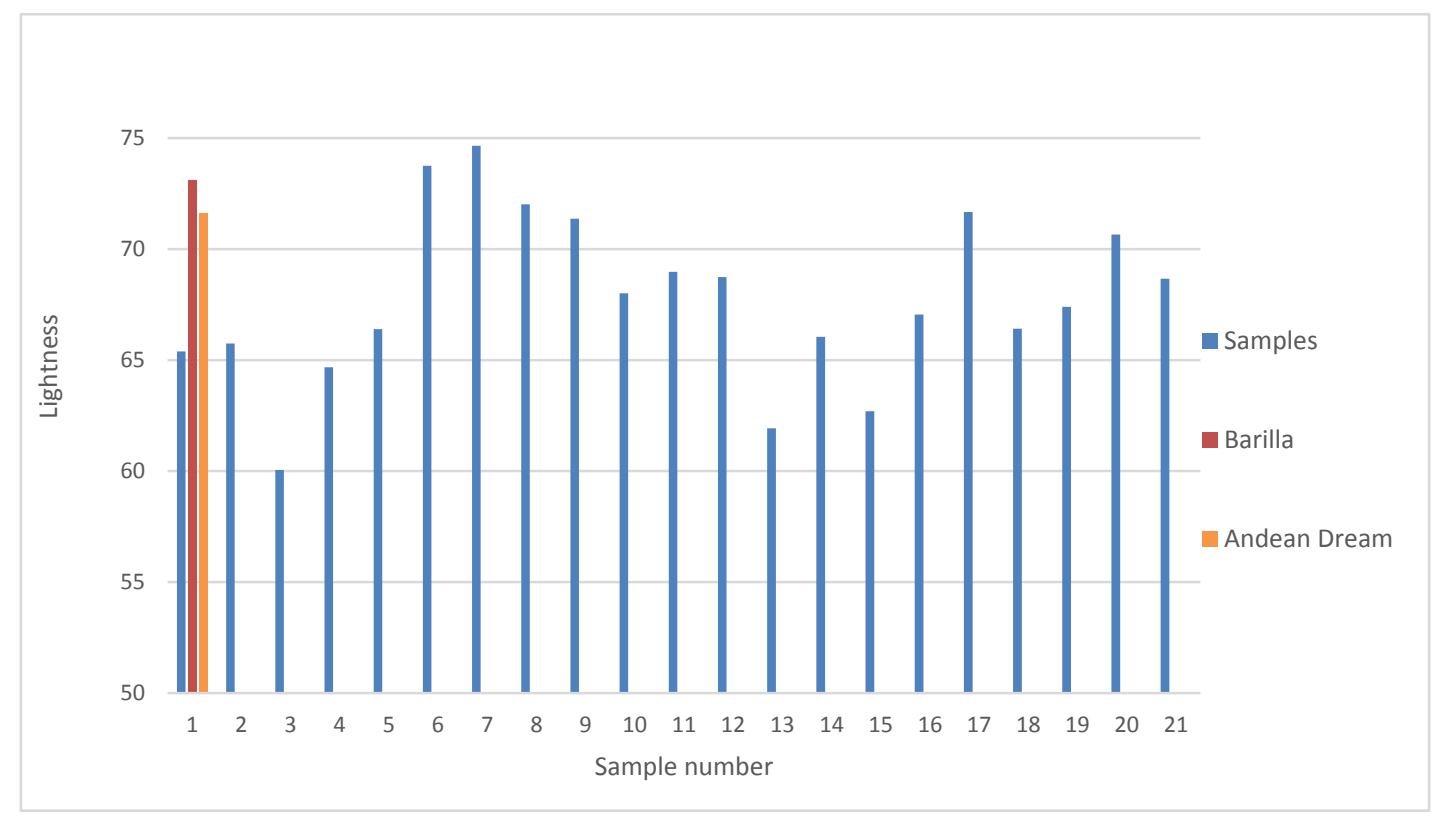

Figure 6. Lightness $\left(\mathrm{L}^{*}\right)$ color results of trial pastas and control pastas

Regarding the $\mathrm{a}^{*}$ and $\mathrm{b}^{*}$ color, results are shown in Table 1 . 
Table 1. Red/green ( $\left.\mathrm{a}^{*}\right)$ and yellow/blue $\left(\mathrm{b}^{*}\right)$ color results of trial pastas and control pastas

\begin{tabular}{lcccc}
\hline \multicolumn{3}{c}{$\mathrm{a}^{*}$} & & $\mathrm{~b}^{*}$ \\
\hline & Mean & Standard deviation & Mean & Standard deviation \\
\hline Samples & 2.95 & 0.49 & 14.14 & 1.28 \\
Barilla & 0.54 & 0.1 & 49.11 & 2.4 \\
AD & -1.06 & 0.24 & 24.46 & 1.8 \\
\hline
\end{tabular}

Even if they were a bit higher, $a^{*}$ value of the samples was approximately the same as the $a^{*}$ value of commercial pasta. Samples' $b^{*}$ value was lower than pasta commercialized $b^{*}$ value. Although the addition of amaranth contributes to the yellowness of the pasta because of the amount of carotenoid pigment and enzymatic reactions (Islas-Rubio et al., 2014), our samples did not have a very high $b^{*}$ value because they contained a little amount of amaranth. According to Belton and Taylor (2010), it also can be due to oxidation during processing: the enzyme lipoxygenase bleaches the yellow carotenoid pigments by oxidation.

The $\Delta \mathrm{E}$ variation between the samples show the difference of color (Figure 7). The graph shows that samples colors were more similar to Andean Dream color because $\Delta \mathrm{E}$ values were lower. Indeed, Barilla pasta were yellower, whereas Andean Dream were whiter, compared to our pastas. $\Delta \mathrm{E}$ analysis via Rcommander showed significant influence $(\mathrm{P}<0.05)$ due to quinoa and amaranth on the product color. Despite the various combinations tested, $\mathrm{R}^{2}$ value was low (35\%), but the software results confirm the assumptions made above. These cereals make the product more or less dark depending on the quantity used.

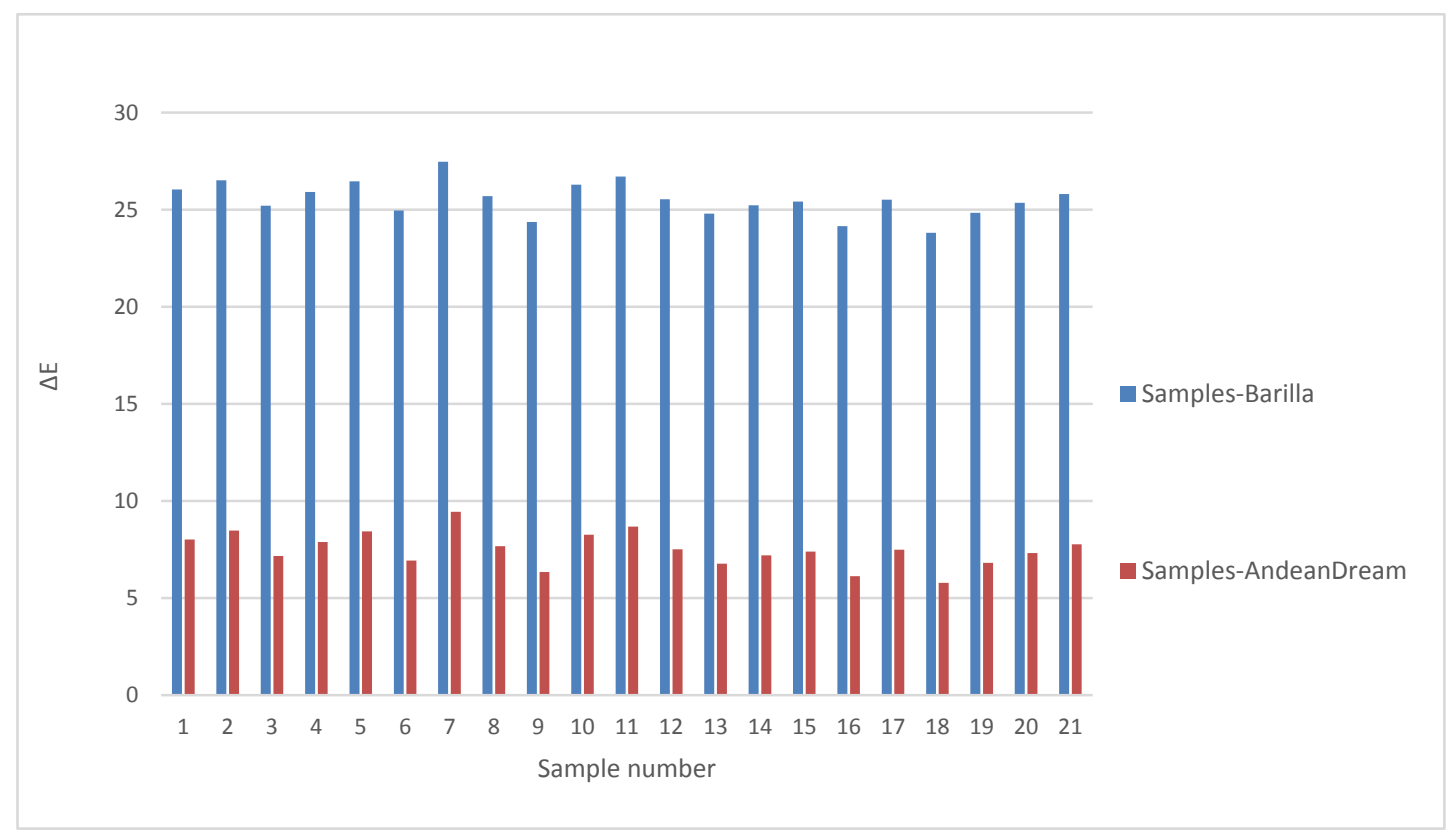

Figure 7. Variation of $\Delta \mathrm{E}$ between our samples and Barilla pastas, or between our samples and Andean Dream pastas

Nevertheless, the parameters $\mathrm{L} *, \mathrm{a} *, \mathrm{~b} *$ were analyzed separately in order to reduce the Type I error risk (Figures 8 and 9).

First of all, luminance analysis confirmed the significant influence of amaranth and quinoa $(\mathrm{P}<0.001)$ as well as their interaction $(\mathrm{P}<0.05)$. Eggs and their interaction with amaranth also had an influence, although lower $(\mathrm{P}<0.1)$ and therefore not taken into account here. This confirms our assumption since $\mathrm{R}^{2}=94 \%$. 


\begin{tabular}{|c|c|c|c|c|c|}
\hline & Estimate & d. Error & t value & $\operatorname{Pr}(>|t|)$ & \\
\hline (Intercept) & 65.33783 & 0.90014 & 72.5862 & $4.601 e-10$ & $* * *$ \\
\hline $\mathrm{x} 1$ & -3.35301 & 0.40291 & -8.3220 & 0.0001633 & $* * *$ \\
\hline $\mathrm{x} 2$ & -6.06204 & 0.40358 & -15.0208 & $5.485 e-06$ & $* * *$ \\
\hline x3 & -0.79922 & 0.40271 & -1.9846 & 0.0944160 & \\
\hline $\mathrm{X} 4$ & 0.63136 & 0.40697 & 1.5514 & 0.1717956 & \\
\hline $\mathrm{x} 1: \mathrm{x} 2$ & 2.73965 & 1.04009 & 2.6340 & 0.0388491 & * \\
\hline$x 1: x 3$ & -0.55332 & 1.16226 & -0.4761 & 0.6508619 & \\
\hline $\mathrm{X} 1: \mathrm{X} 4$ & 0.18619 & 1.21832 & 0.1528 & 0.8835435 & \\
\hline $\mathrm{x} 2: \mathrm{X} 3$ & -2.64488 & 1.16204 & -2.2761 & 0.0631387 & . \\
\hline $\mathrm{X} 2: \mathrm{X} 4$ & 1.51906 & 1.23757 & 1.2275 & 0.2656198 & \\
\hline $\mathrm{X} 3: \mathrm{X} 4$ & 1.34450 & 1.21226 & 1.1091 & 0.3098566 & \\
\hline $\mathrm{x} 1^{\wedge} 2$ & 4.40423 & 1.10282 & 3.9936 & 0.0071709 & ** \\
\hline$x 2^{\wedge} 2$ & -0.35929 & 1.10263 & -0.3259 & 0.7555996 & \\
\hline$x 3^{\wedge} 2$ & 3.58940 & 1.07030 & 3.3536 & 0.0153502 & * \\
\hline$x 4^{\wedge} 2$ & 2.42482 & 1.06761 & 2.2713 & 0.0635570 & \\
\hline
\end{tabular}

Figure 8. Luminance results via Rcommander using SO() design
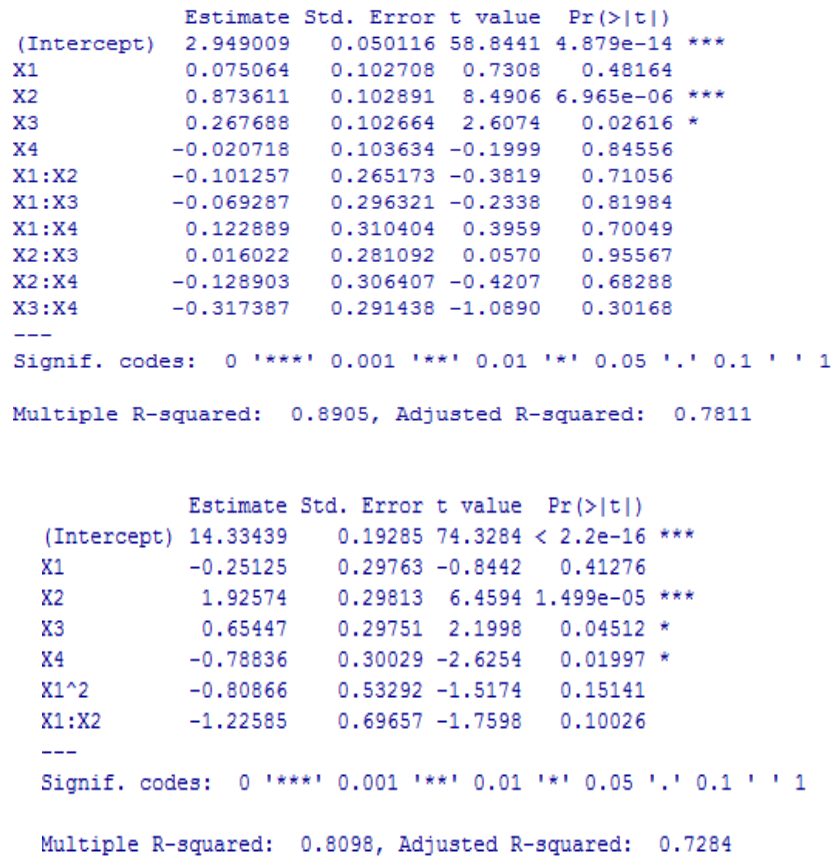

Figure 9. a* results with $\mathrm{SO}()$ design on the left, and b* results with $\mathrm{FO}(\mathrm{X} 1, \mathrm{X} 2, \mathrm{X} 3, \mathrm{X} 4)+\mathrm{TWI}(\mathrm{X} 1, \mathrm{X} 2)+\mathrm{PQ}(\mathrm{X} 1)$ design on the right

The $a^{*}$ value, which represent the range of colors from green to red, would appear to be influenced by the amount of amaranth $(\mathrm{P}<0.001)$ and egg white $(\mathrm{P}<0.05)$. Regarding $\mathrm{b}^{*}$ value (color range from blue to yellow), it would appear to be influenced by the amount of amaranth $(\mathrm{P}<0.001)$, egg whites and water individually $(\mathrm{P}<0.05)$. These results are consistent with those obtained in Belton and Taylor (2010) which has shown that the addition of amaranth gives a yellow color to the dough due to the intake of carotenoid. Egg whites also influence color since it provides a whitish hue. Thus, it is quite logical to see the influence of these two factors.

\subsection{Water Activity}

Water activity $\left(\mathrm{a}_{\mathrm{w}}\right)$ represents the water available in the product. Free water is the part of the whole water contained in a product which can participate to biochemical reactions or which can be used by microorganisms. Thus, the higher the water activity value is, the higher the product can be contaminated. Table 2 shows the measurement results. 
Table 2. Water activity of trial pastas and control pastas

\begin{tabular}{lcc}
\hline & & $\mathrm{a}_{\mathrm{w}}$ \\
\hline & Mean & Standard deviation \\
\hline Samples & 0.59 & 0.02 \\
Barilla & 0.62 & 0.01 \\
AD & 0.57 & 0.01 \\
\hline
\end{tabular}

For our samples, $a_{w}$ were between Barilla and Andean Dream $a_{w}$. It seems that our pasta $a_{w}$ was adequate, and thus they were shelf stable. Moreover, according to Ayadi et al. (2011) a product is considered stable with long storage stability with a water activity equal to or less than 0.6 . Only three samples (number $4,8,9$ ) had an $a_{w}$ higher than 0.6, thus the other samples which had low water activity could support a long storage times without the risk of fast spoilage (Islas-Rubio et al., 2014).

Data analysis via Rcommander confirmed the hypothesis that none of factors had an influence on samples water activity value, with a Type I error of $0.05 \%$. Furthermore, with a Type I risk by $0.01 \%$, interactions between quinoa and eggs and amaranth and eggs seem to influence this value. But, we choose to focus only on risk by $0.05 \%$ or less, so it appeared that none of factors had particular influence on the water activity of the final product. This was readily determined from the previous graph, since the $\mathrm{a}_{\mathrm{w}}$ values were very close to each other.

\subsection{Optimal Cooking Time}

The method used to determine optimum cooking time for pastas samples is quite uncertain so the OCT was determined in three duplicates for each sample to refine the best cooking time interval. The cooking time for all samples was lower (about $7 \mathrm{~min}$ ) than the commercial gluten-free pastas (14 min for Barilla and 17-18 min for Andean Dream pastas). Gluten network seems to be more reproduced in commercial pasta than in ours. Consequently, a protective layer formed on the surface of spaghetti. Thus, the water needs more time to reach the spaghetti matrix, mainly the spaghetti center. That is why the optimal cooking time is longer with commercial gluten-free spaghetti.

Analysis of our experimental design has shown that the quantity of water and egg whites had an influence on the cooking time. Moreover, the interaction between grains and water also had an effect $(\mathrm{P}<0.05)$. Indeed, depending on the amount of each factor the dough had a protein structure more or less similar to that present in traditional pasta. For example, the addition of eggs reduces the penetration of water into dough and thus increases the cooking time.

\subsection{Water Absorption}

During drying, denaturalization, polymerization and aggregation of proteins allowed to create a solid film on spaghetti surface. But during boiling, this film is perturbed by cooking water which penetrates into the protein matrix. Moreover, in the other hand, starch granules absorb water and swell. Consequently, the volume of pasta increased. According to Bustos et al. (2015), they are considered acceptable if they absorb 150-200g of water/100g pasta namely a water absorption between 150 and 200\%. Nevertheless, Donnelly (1979) reported that a mass increase could be comprised between 200 and 250\% and Hummel (1966) cited a minimum value of $100 \%$.

Andean Dream pasta showed a WA of $94 \%$ (Figure 10), which was not very acceptable. But, according to Rosa et al. (2015), the mass increase of the pasta depends upon cooking time, shape, and quality. Barilla WA was $155 \%$ which was clearly acceptable. Our samples range between 108 and $190 \%$ with an average of $151 \%$, so we can say that they were all acceptable because there were all between 100 and $200 \%$. 


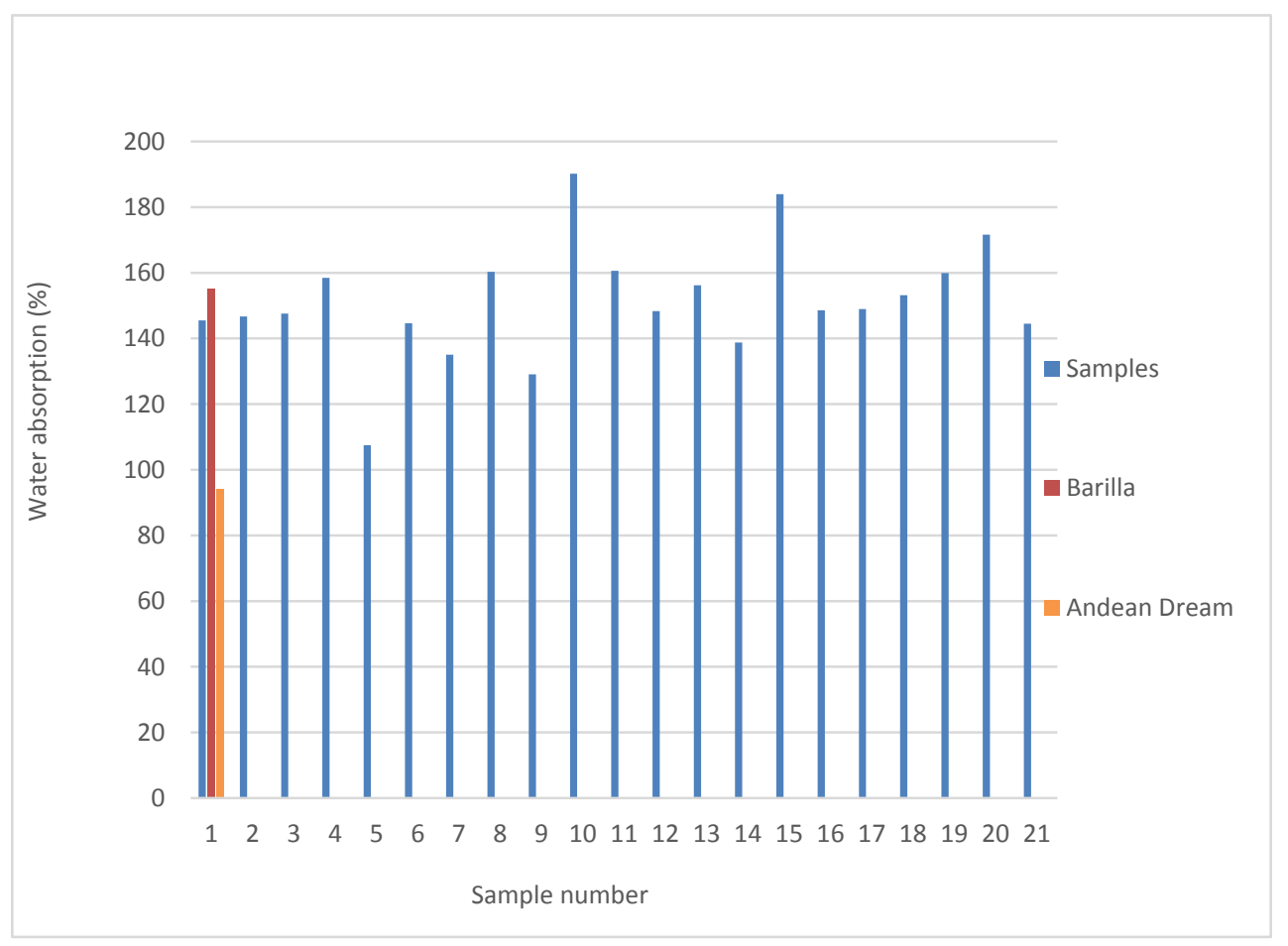

Figure 10. Water absorption (WA) of trial pastas and control pastas

Data processing via Rcommander showed that water absorption was influenced by the interaction between amaranth and quinoa and between quinoa and water $(\mathrm{P}<0.05)$ but it was more greatly influenced by the interaction between amaranth and water $(0.001 \%)$. Indeed, as mentioned above, the protein network was less strong in the case of gluten-free pasta and this influence the water penetration during cooking (protein film disturbed during penetration of water). Data suggest that the protein network was more or less acceptable depending on the amount of different grains. Indeed, the greater the rice quantity, the greater the water absorption. It was the opposite for amaranth and quinoa.

\subsection{Cooking Loss}

The quantity of solids which migrates into the water during cooking is also an important factor for quality pasta products (Figure 11). Main structuring agents of pastas are starch and proteins, and the original point of cooking losses is often due to excessive starch swelling. Good quality pastas are made of a protein network able to withstand starch swelling during cooking. Delcour et al. (2012) showed that an optimal cross-linked protein network functions as a continuous framework, starch is trapped so starch swelling is restricted and cooking losses are minimized. To sum up, the more the protein network is developed, the lower the CL.

Barilla spaghettis seems to be good quality pastas because they had low CL (Figure 11) (10.3\%) whereas, once again, Andean Dream pasta could be considered poor quality pasta because of their high CL (27.5\%). All samples had different CL value, but the majority range between 15 and $20 \%$. Only three samples had a CL greater than $20 \%$ (number 7, 9 and 17) and should not be choose as best formulation.

In wheat pasta the cooking loss is typically lower than $8 \%$, but the lack of gluten in gluten-free pasta can cause an increase in CL and a decrease in firmness because the starch polymers are less linked to the matrix (Marti et al., 2014). Also, Tudorica et al. (2002) showed that increasing of cooking loss could be caused by fibers which use a higher water quantity. Thus, there would be less water available for the starch swelling. CL values for our samples seems to be acceptable according to literature. 


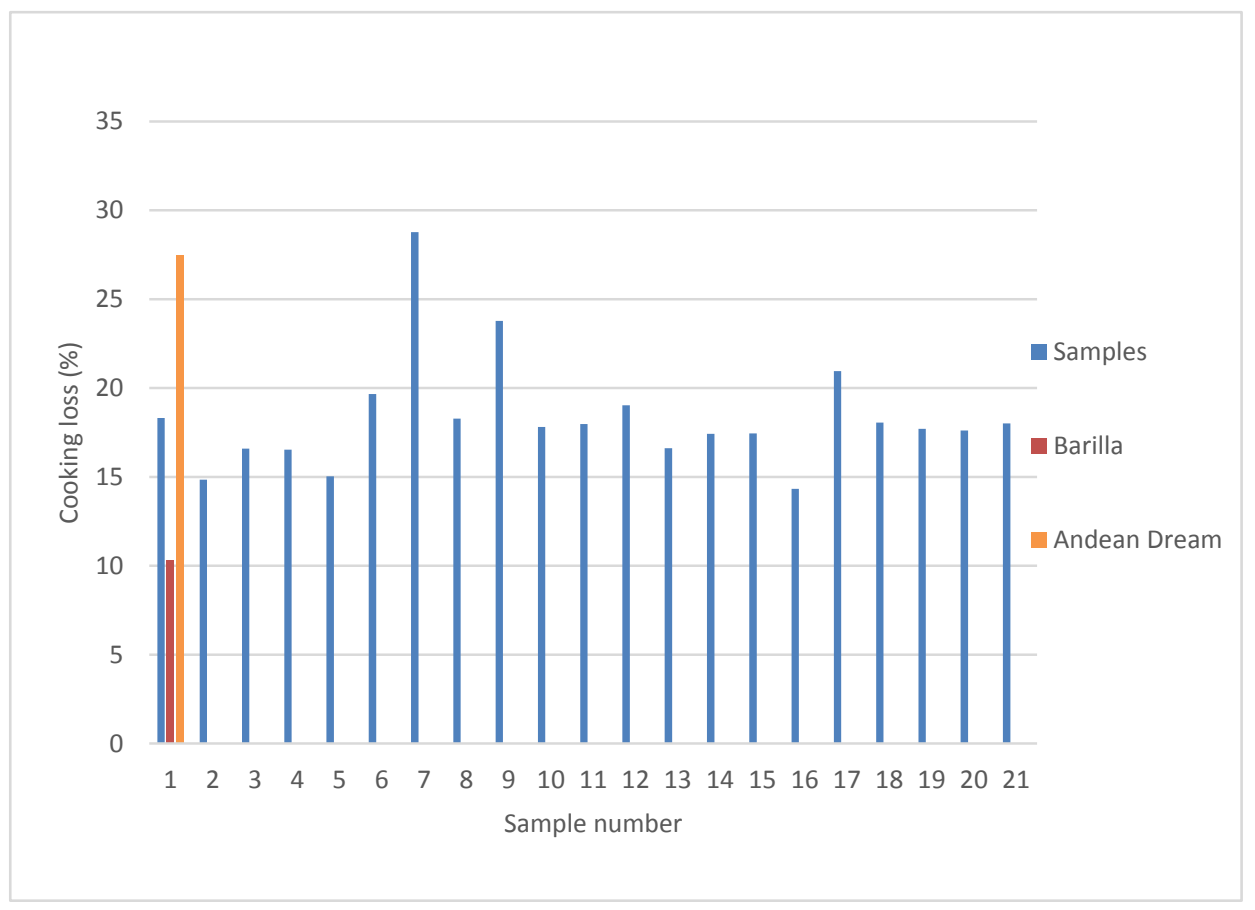

Figure 11. Cooking loss of trial pastas and control pastas

Data analysis via Rcommander software showed which variables influenced cooking losses. The results are represented in Figure 12. We can see that factors X1, X2 individually but also in interaction $(\mathrm{P}<0.01)$ influence cooking losses. Indeed, depending on the type of grains the amount of starch is different and it is primarily responsible for cooking losses. Typically, FAO (1993) data that rice contains $90 \%$ starch while amaranth and quinoa contain $60 \%$, so there should be more cooking losses when there is rice. The quantity of water also seems, less importantly, to influence cooking losses $(\mathrm{P}<0.01)$.

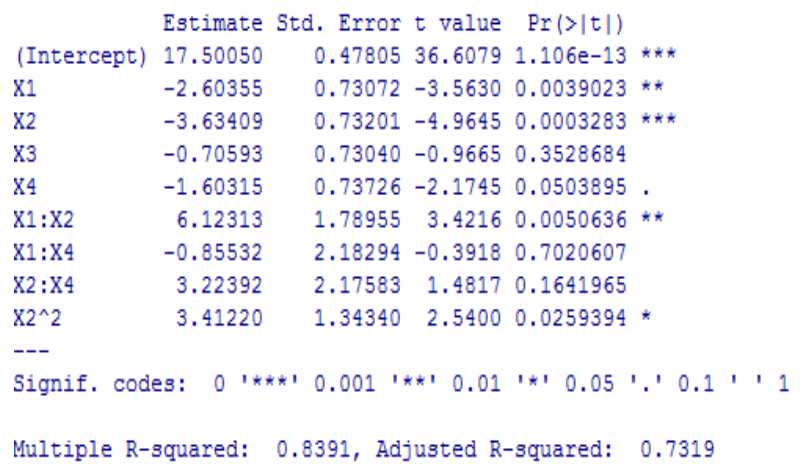

Figure 12. Cooking loss analysis via Rcommander software using $\mathrm{FO}(\mathrm{X} 1, \mathrm{X} 2, \mathrm{X} 3, \mathrm{X} 4)+\mathrm{TWI}(\mathrm{X} 1, \mathrm{X} 2, \mathrm{X} 4)+\mathrm{PQ}(\mathrm{X} 2)$ design

\subsection{Texture Analysis}

Texture is a main concern of consumers, with sticky, soft pasta being generally unacceptable. A firm but elastic product is desired, that is, pasta that is "al dente" (Hager et al., 2012). 


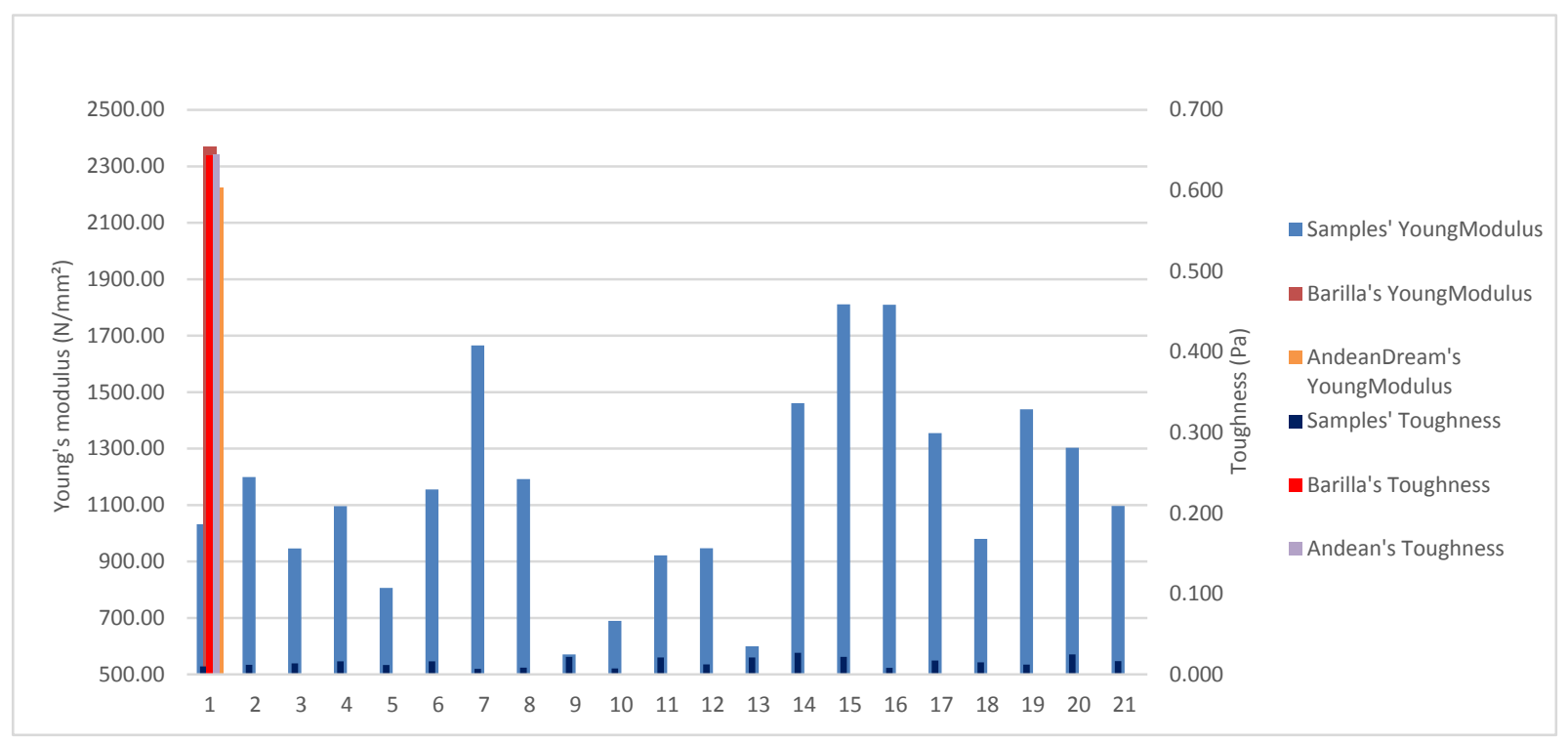

Figure 13. Young's modulus and toughness of trial pastas and control pastas

As we can see (Figure 13), there were large texture differences between our samples and commercialized pastas. Barilla and Andean Dream's spaghettis had similar texture, indeed, their Young's modulus and toughness values were close. Nevertheless, Young's modulus was lower in our samples: it lasts from 560 to $1811 \mathrm{~N} / \mathrm{mm}^{2}$ whereas it was about $2369 \pm 353 \mathrm{~N} / \mathrm{mm}^{2}$ and $2265 \pm 1000 \mathrm{~N} / \mathrm{mm}^{2}$ for Barilla and Andean Dream, respectively. Regarding the elasticity, it appears that samples 7, 14, 15, 16 and 19 were closest to commercialized pastas' elasticity. Furthermore, samples' toughness was really low compared to Barilla and Andean Dream pastas (difference of 97\%). Thus, this parameter needs to be reconsidered. One solution might be to add an emulsifier in the recipe, indeed, the study of Schoenlechner et al. (2010) has shown that adding an emulsifier besides egg whites improve the texture. Considering elasticity and toughness, it seems that sample 15 was the one which had the best texture.

Only the Young's modulus $\left(\mathrm{R}^{2}=33 \%\right)$ was selected after data analysis via Rcommander because results for toughness were not reliable with a $\mathrm{R}^{2}$ by $1 \%$. Young's modulus analysis is presented below in Figure 14.

It seems that factors had no impacts individually, but X2:X4 and X1:X2 interactions had a significant influence $(\mathrm{P}<0.05)$ on the elasticity of the product. However, these results remain uncertain since the $\mathrm{R}^{2}$ was low. Moreover, eggs should normally have an influence on product's texture: indeed, eggs start to "gelified" at a certain temperature $\left(60^{\circ} \mathrm{C}\right)$. Furthermore, it is possible that the ambient air drying was not suitable for it's processing, and perhaps we should practice a shorter drying at higher temperature.

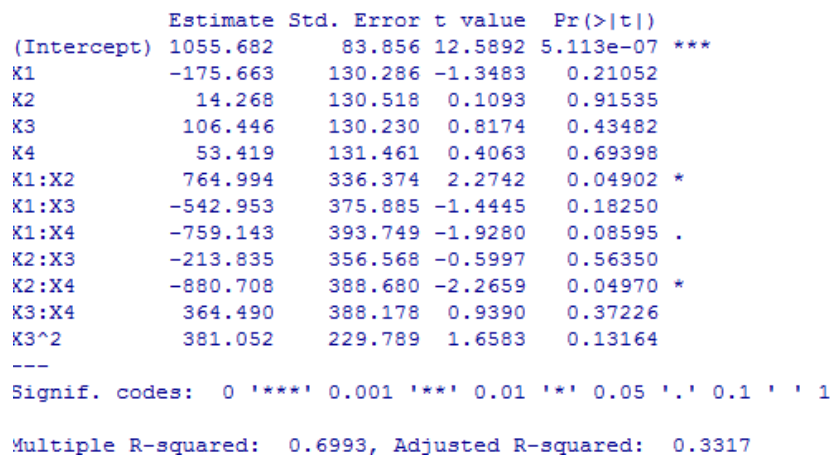

Figure 14. Young's modulus analysis using $\mathrm{FO}(\mathrm{X} 1, \mathrm{X} 2, \mathrm{X} 3, \mathrm{X} 4)+\mathrm{TWI}(\mathrm{X} 1, \mathrm{X} 2, \mathrm{X} 3, \mathrm{X} 4)+\mathrm{PQ}(\mathrm{X} 3)$ design

\subsection{Best Formulation Choice}

Doehlert's experimental design belongs to plans for response surface; thus, graphical analysis allows numerous 
additional information. In view of the previous results, it seems that CL, texture, color and Oct were the only parameters that had to be considered to optimize the recipe. In fact, other parameters do not seem to be influenced by any of the factors X1, X2, X3, X4. In order to find the best formulation, different graphs have been developed. The optimal values for each factor could be determined step by step, testing the various possible formulations and observing their impact on the value of the parameters. The study began with cooking losses (major parameter for quality assessment) followed by texture, color, and cooking time. The 3D graph $\mathrm{X} 1=\mathrm{f}(\mathrm{X} 2)$ was traced for CL, which must be minimized (nearly 10\%), since these two parameters influence them. Each time, the values of $\mathrm{X} 3$ and $\mathrm{X} 4$ factors varied from +1 to -1 in order to visualize the impact. All combinations were tested and results show that to have minimal cooking losses, $\mathrm{X} 4$, which correspond to the amount of water added, must be equal to 1 , which corresponds to $39 \%$. These data did not allow to define an optimal value for the others factors. Nevertheless, X2 seems to be between -0.5 and -1 .

Color graphical analysis $\left(L^{*}, a^{*}, b^{*}\right)$ was carried out by testing the various possible settings. $b^{*}$ results showed that X3 value should always be maximum. Thus, in addition to a maximum amount of water (39\%), the optimal formulation must also have a maximum amount of egg whites (18\%). However, to maximize this parameter, it should have a maximum X2, which was contrary to previous analyzes. Maintaining X4 and X3 maximum and $\mathrm{X} 2$ between -1 and -0.5 , luminance results indicate that X1 should be between -1 and -0.5 . The X1 and X2 values were therefore still unknown.

The elasticity should be maximized to reach a value of $2300 \mathrm{~N} / \mathrm{mm}^{2}$. To visualize how factors should vary, $\mathrm{X} 1=\mathrm{f}(\mathrm{X} 2)$ and $\mathrm{X} 2=\mathrm{f}(\mathrm{X} 4)$ were plotted. Results showed that, for maximum $\mathrm{X} 4$ and $\mathrm{X} 3, \mathrm{X} 2$ value must be between -0.5 and -1 in good agreement with the results obtained for cooking losses. X1 value would seem to be between 0 and -1 . However, these values cannot be guaranteed by $100 \%$ since the $\mathrm{R}^{2}$ was only $33 \%$.

Finally, the graphical analysis of the setting "optimal cooking time" was conducted by plotting $\mathrm{X} 1=\mathrm{f}(\mathrm{X} 4)$ and $\mathrm{X} 2=\mathrm{f}(\mathrm{X} 4)$. Results demonstrated that to maximize it, the formulation would have $\mathrm{X} 1[-1 ;-0.5]$, with $\mathrm{X} 2$ between -1 and -0.5 and $\mathrm{X} 3$ and $\mathrm{X} 4$ equal 1 .

Thus, according to this study, the ideal formulation should consist of $39 \%$ water and $18 \%$ of eggs but grains ratio was still unknown. In order to define it, the different graphics selected for each parameter were plotted and compared. The parameters $\mathrm{b} *$ and $\mathrm{a} *$ in the colorimetric analysis provided no information at the X1 and X2 values. Results are shown in Figure 15.

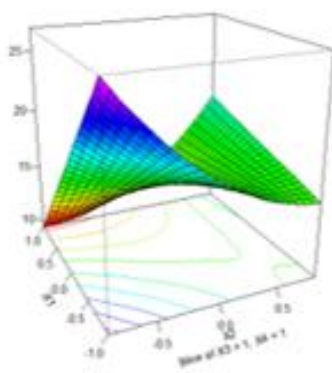

A

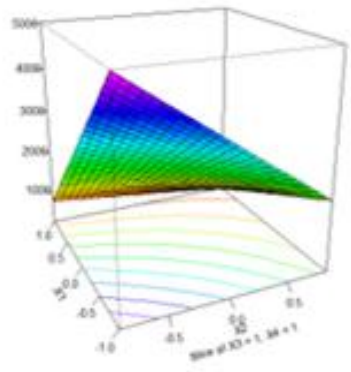

$\mathrm{R}$

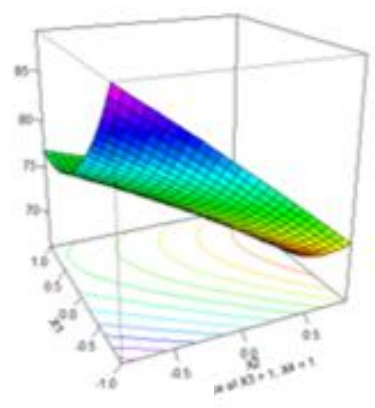

$\mathrm{C}$

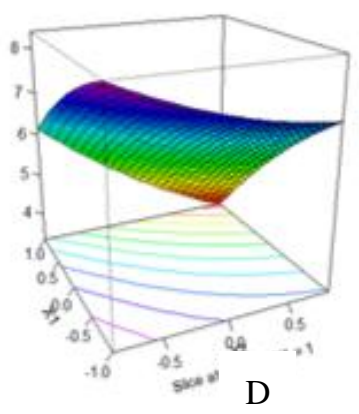

$\mathrm{D}$

Figure 15. Graph $\mathrm{X} 1=\mathrm{f}(\mathrm{X} 2)$ with $\mathrm{X} 3$ and $\mathrm{X} 3$ equal $1 . \mathrm{A}=\mathrm{CL}, \mathrm{B}=$ Young's modulus, $\mathrm{C}=$ Luminance, $\mathrm{D}=\mathrm{OCT}$

To minimize CL, it would have a large amount of X1 (equal to 1) and a very small quantity of X2 (equal to -1). Regarding Young's modulus (about $2300 \mathrm{~N} / \mathrm{mm}^{2}$ ), maintainning X2 between -1 and -0.5 , X1 should be between -1 and 0.5 . Having a luminance of about 73 , would require an amount of X2 between -1 and -0.5 regardless of the X1 value. Finally, to maximize the cooking time, it would have amounts of amaranth and quinoa very low. Thus, all data taking into account, the selected optimal value of X1 was 0.5 , which means $40 \%$ quinoa. This value meets the texture and color settings while it was slightly lower than provided value to minimize CL and larger than desired value to maximize the cooking time. Indeed, the latter parameter was not the most important for quality assessment. The same reasoning was done for $\mathrm{X} 2$ factor; the selected optimal value was 0.5 that means $10 \%$ of amaranth.

In conclusion, the ideal formulation was composed of $50 \%$ rice, $40 \%$ quinoa, $10 \%$ amaranth, $18 \%$ egg whites, 
and 39\% water. Once prepared the ideal formulation prepared, its physical and chemical characteristics were measured and compared with those of Barilla pastas (Table 3).

Table 3. Physical property comparisions between Barilla pasta and our optimal formulation

\begin{tabular}{lcc}
\hline & Optimal Formulation & Barilla \\
\hline $\mathrm{a}_{\mathrm{w}}$ & 0.52 & 0.62 \\
OCT (min) & 7.0 & 13.8 \\
$\mathrm{~L}^{*}$ & 65.32 & 73.12 \\
$\mathrm{a}^{*}$ & 3.18 & 0.54 \\
$\mathrm{~b}^{*}$ & 17.23 & 49.11 \\
Delta E & 56.1 & 32.9 \\
Unit density $\left(\mathrm{kg} / \mathrm{m}^{3}\right)$ & 1272 & 1436 \\
Young's modulus $\left(\mathrm{N} / \mathrm{mm}^{2}\right)$ & 2137 & 2369 \\
WA $(\%)$ & 161 & 155 \\
CL $(\%)$ & 14.0 & 10.3 \\
MC $(\%)$ & 11.83 & 9.13 \\
\hline
\end{tabular}

Both spaghettis had similar properties, except for the OCT which was divided by 2 in our formulation. This parameter in itself was not critical and did not appear to influence the other, so a 7-minute cooking time was deemed acceptable. $b^{*}$ value could be from -120 to +120 , so the difference was supposed to be negligible. Regarding water activity, that of our preparation was lower than 0.6 (Ayadi et al., 2011). Compared to this parameter, it would seem that gluten-free Barilla pastas were not acceptable. Regarding color, both had high L* value: therefore, they had a light color that should appeal to consumers. Best formulation's unit density was slightly lower than Barilla's UD which means that these pastas contain less air and this could influence the texture in the mouth. Nevertheless, this small difference was not significant. Regarding Young's modulus values, they were all close. However, a texture difference was clearly visible to the naked eye and to the touch: it therefore appears that this was not the elasticity but the product firmness should be improved. Water absorption was higher than $150 \%$. Similarly, pastas were acceptable according to their moisture content, which were lower than $12.5 \%$ (Bustos et al., 2015). The cooking losses were reduced (they were between 15 and 20\% formerly) and were thus suitable.

\subsection{Sensory Analysis}

First part of the sensory analysis was to assess pastas according to different parameters. Results, after statistical analysis, are shown in Table 4.

Table 4. Statistical analysis of hedonic tests conducted on Barilla and Andean Dream pastas vs. our best formulation

\begin{tabular}{llccc}
\hline & & Barilla & Andean Dream & Best formulation \\
\hline \multirow{2}{*}{ Appearance } & Mean & 3.7 & 3.8 & 3.6 \\
& Standard deviation & 1.3 & 1.2 & 0.7 \\
Color & Mean & 3.8 & 3.6 & 3.5 \\
& Standard deviation & 1.4 & 1.2 & 1.1 \\
\multirow{2}{*}{ Odor } & Mean & 3.4 & 3.7 & 3.1 \\
\multirow{2}{*}{ Taste } & Standard deviation & 1.1 & 1.1 & 1.1 \\
\multirow{4}{*}{ Texture } & Mean & 3.7 & 4.0 & 3.4 \\
\multirow{2}{*}{ Overall acceptability } & Standard deviation & 1.1 & 0.8 & 1.3 \\
& Mean & 4.4 & 3.8 & 3.3 \\
& Standard deviation & 1.1 & 1.0 & 1.4 \\
& Standard deviation & 3.8 & 3.8 & 3.2 \\
& & 1.1 & 0.8 & 1.1 \\
\hline
\end{tabular}

Differences between our formulation and commercialized pasta were not very large. Regarding product appearance, results were close and best formulation's standard deviation was lower than those of Barilla and Andean Dream pastas. So it seems that the product made with rice, quinoa and amaranth was visually pleasing, 
as well at its color. In terms of smell and taste, those of our pastas were slightly less preferred, this probably stems from the fact that they were composed of unusual cereals. Indeed, some consumers found that smell and taste were too herbaceous. Nevertheless, standard deviations were rather high: the subjects being untrained, thus their rating varies according to their personal taste.

Obviously, the texture rating for the best formulation was lower. This was entirely predictable in view of the results of physicochemical analyzes. Consumers think that the texture was too viscous. Finally, the overall acceptability score was identical to both commercialized pastas with a value of 3.8/5 while ideal formulation achieves a score of 3.2/5. Thus, according to the ratings, it appears that the main criterion to improve was the texture. The taste and smell may also be improved, but opinions were very diverse about these parameters.

To analyze the ranking test, Friedman coefficient were calculated and compared to the Friedman critical value. Results are shown in Table 5.

Table 5. Results of the ranking test. Friedman coefficient calculated and Friedman critical value using a Type I error rate of $5 \%$

\begin{tabular}{|c|c|c|}
\hline & With sauce & Without sauce \\
\hline Friedman coefficient & 0.5 & 11.4 \\
\hline Friedman critical value & & \\
\hline
\end{tabular}

Without sauce, pastas were perceived differently as Friedman coefficient calculated was higher than Friedman critical value, read directly in the table. Nevertheless, Fcalculated < Fcritical when pastas were served with tomato sauce: consumers fail to perceive a difference between spaghettis. Indeed, the sauce can mask the grassy taste and reduce the stickiness' sensation in the homemade product.

Each panelist also had to indicate if they were ready to eat these different pastas again. The results are illustrated in Figure 16.
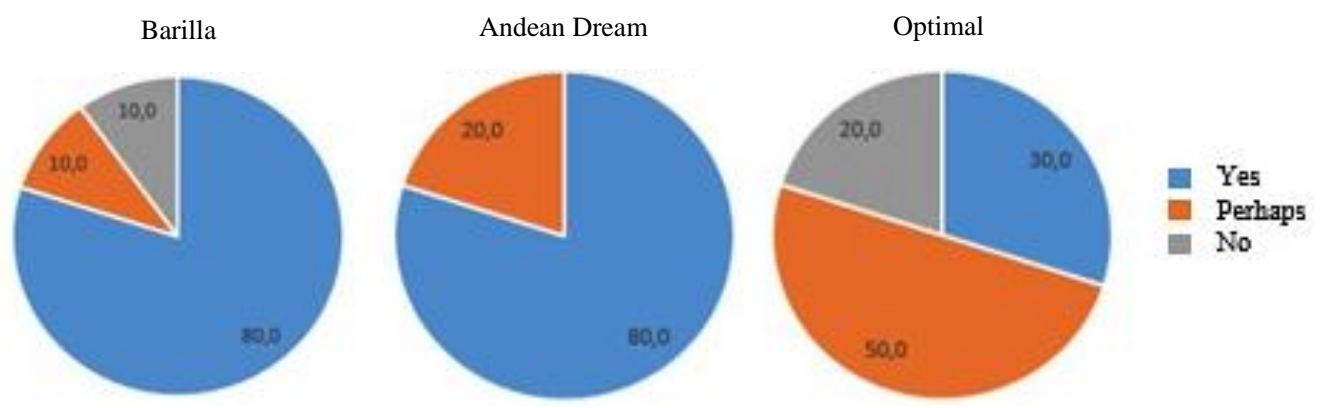

Figure 16. Pie chart illustrating the percentage of consumers ready (or not) to eat the products again

It appears that $80 \%$ of consumers would be willing to consume again Barilla or Andean Dream pastas while the result was only by $30 \%$ for the ideal formulation. But, $50 \%$ these pastas still had a mixed review. Furthermore, this question was asked in the first part of the test, but it would have been wiser to ask it at the end, after consumers had tasted the pastas with tomato sauce: the number of positive responses would certainly have been higher.

In conclusion, it seems that opinions were divergent for the optimal formulation: it pleases some while others do not appreciate it. However, with the addition of sauce, opinions were unanimous and the optimal formulation was placed at the same level as commercialized pastas. Some settings must be improved, especially the texture of the product. If the project continues, it would be interesting to add additives to achieve a firmer and less sticky product.

\section{Conclusions}

The goal of this study was to formulate good quality gluten-free spaghettis made up of rice, quinoa and amaranth. Optimizing the best formulation, quality product with acceptable parameters was obtained with the following formulation: $50 \%$ of rice, $40 \%$ of quinoa, $10 \%$ of amaranth, $18 \%$ of egg whites and 39\% of eggs. Indeed, a 
significant amount of rice achieves white spaghettis that attract consumers. Nevertheless, it was necessary to mix the rice with other grains in order to reduce cooking loss. Amaranth and quinoa have both interesting nutritional properties but amaranth had a stronger taste and can bring a musty taste in proportion (Schoenlechner et al., 2010), so the amount was minimal. The addition of egg whites was essential since it allows production of better texture.

With this formulation, the physicochemical parameters were acceptable and were closer than those obtained for Barilla gluten-free pastas. However, some parameters still need to be improved, especially the texture. First of all, in order to ameliorate this setting, we should use flour with a finer grinding. We could choose to only keep flour with a diameter under $500 \mathrm{~nm}$ : indeed, when we buy flour in store the diameter was never greater than $500 \mathrm{~nm}$. Secondly, adjusting drying process could improve pastas texture. Instead of drying pastas $24 \mathrm{~h}$ at ambient temperature, it could be better to use a drying process with a higher temperature during a short time. Indeed, studies have shown that a drying process in an oven can improve pastas texture: $42^{\circ} \mathrm{C}$ for at least $9 \mathrm{~h}$ (Schoenlechner et al., 2010) or $20 \mathrm{~min}$ at $55^{\circ} \mathrm{C}+10 \mathrm{~h}$ at $75^{\circ} \mathrm{C}+40 \mathrm{~min}$ at $60^{\circ} \mathrm{C}+20 \mathrm{~min}$ at $45^{\circ} \mathrm{C}+14 \mathrm{~h}$ at $40^{\circ} \mathrm{C}$ (Padalino et al., 2012). We might also consider adding one or several types of emulsifier to the dough (like guar gum or monoglycerides). Indeed, coupled with eggs, it appears in Schoenlechner et al. (2010) study that the addition of an emulsifier allows to obtain spaghettis with better texture (firmer) and more stability during cooking (less losses). Also, the extrusion process using extruder could improve protein structure and thus texture of spaghetti since the energy imparted to the dough would be greater than that applied during the extrusion process via the Kitchen Aid.

According to sensory analysis, it appears that the optimal formulation (made up of rice, quinoa and amaranth), even if it had characteristics similar to those of marketed gluten-free pastas, still needed improvement. Indeed, consumers think that the texture was too sticky and not enough firm and soft. In contrast, in terms of taste, the ideal formulation was acceptable: with the addition of tomato sauce, no difference between the three types of spaghettis was perceived.

Thus, according to this study, we can say that gluten-free pastas composition was not easy to find. Indeed, each gluten-free grain has different properties which may influence the quality. In order to find best gluten-free pastas formulation, it was important to mix different cereals in order to try to just keep their advantages and to limit bad consequences. The water quantity added in the recipe was important and it must not be chosen at random. Also, the recipe must contain egg whites since they offer a better texture to the product. Nevertheless, it was really difficult to obtain a firm and soft product, indeed, in traditional pastas this texture was create by the gluten which provides a good protein network. Without its use, we were able to have a good elasticity but not a good toughness in the product. This last parameter must be improved.

\section{References}

Ayadi, F. Y., Muthukumarappan, K., Rosentrater, K. A., \& Brown, M. L. (2011). Twin-screw extrusion processing of rainbow trout (Oncorhynchus mykiss) feeds using various levels of corn-based distillers dried grains with solubles (DDGS). Cereal Chemistry, 88(4), 363-374).

Belton, P., \& Taylor, J. (2010). Pseudocereals and Less Common Cereals - Grain Properties and Potential Utilization. Berlin, Germany: Springer.

Broz, R., \& Horne, T. (2007). Gluten-free product development. Cereal Foods World, 52(3), 148-149.

Bustos, M. C., Perez, G. T., \& Leon, A. E. (2015). Structure and quality of pasta enriched with functional ingredients. RSC Adv. 5, 30780-30792.

Delcour, J. A, Joye, I. J., Pareyt, B., Wilderjans, E., Brijs, K., \& Lagrain, B. (2012). Wheat gluten functionality as a quality determinant in cereal-based food products. Annual Rev Food Sci Technol, 3, 469-492.

Dicke, W. K. (1950). Celiac disease investigation of the harmful effects of certain types of cereal on patient with celiac disease. Ph. D. Thesis, State University of Utrecht.

Donnelly, B. J. (1979). Pasta products: raw material, technology, evaluation. The Macaroni Journal, 61(1), 6-7, $10,12,14-15,18$.

Engleson, J., \& Atwell, B. (2008). Gluten-free product development. Cereal Foods World, 53(4), 180-184.

FAO. (1993). Rice in human nutrition. chapter 3. Grain structure, composition and quality. Rome, Italy: Food and Agriculture Organization of the United Nations. Available online:

http://books.irri.org/9251031495_content.pdf.

Chillo, S., Laverse, J., Falcone, P. M., \& Del Nobile, M. A. (2007) Effect of carboxymethylcellulose and 
pregelatinized corn starch on the quality of amaranthus spaghetti. Journal of Food Engineering, 83, 492-500.

Gibson, L. J., \& Ashby, M. F. (1988). Cellular solids : Structure \& properties. Advances in Polymer Technology, 9(2), 165-166.

Hager, A. S., Lauck, F., Zannini, E., \& Arendt, E. K. (2012). Development of gluten-free fresh egg pasta based on oat and teff flour. European Food Research and Technology, 235(5), 861-871.

Hummel, C. (1966). Macaroni Products. London: Food Trade Press.

Inglett, G. E, Chen, D., \& Sean, X. L. (2015). Antioxidant activities of selective gluten free ancient grains. Food and Nutrition Sciences, 6, 612-621.

Islas-Rubio, A. R., Calderon De La Barca, A. M., Cabrera-Chavez, F., Cota-Gastellum, A., \& Beta, T. (2014). Effect of semolina replacement with a raw: popped amaranth flour blend on cooking quality and texture of pasta. LWT - Food Sciences and Technology, 57, 217-222.

Marti, A., Barbiroli, A., Marengo, M., Fongaro, L., Iametti, S., \& Pagani, M. A. (2014). Structuring and texturing gluten-free pasta: egg albumen or whey proteins? European Food Research and Technology, 238, 217-224.

Mokryzcki, W., \& Tatol, M. (2011). Color difference Delta E - A survey. Machine Graphics and Vision, 20(4), 383-411.

Padalino L, Mastromatteo, M., Lecce, L., Cozzolino F., \& Del Nobile, M. A. (2012). Manufacture and characterization of gluten-free spaghetti enriched with vegetable flour. Journal of Cereal Science, 57(3), 333-342.

Rosa, C. S., Prestes, R. C., Tessele, K., \& Crauss, M. (2015) Influence of the different addition levels of amaranth flour and rice flour on pasta buckwheat flour. International Food Research Journal, 22(2), 691-698.

Rosentrater, K. A., Richard, T. L., Bern, C. J., \& Flores, R. A. (2005). Small-scale extrusion of corn masa by-products. Cereal Chemistry, 82, 436-446.

Sabanis, D., \& Tzia, C. (2011). Effect of hydrocolloids on selected properties of gluten-free dough and bread. Food Science and Technology International, 17(4), 279-291.

Schoenlechner, R., Drausinger, J., Ottenschlaeger, V., Jurackox K., \& Berghofer, E. (2010). Functional properties of gluten-free pasta produced from amaranth, quinoa and buckwheat. Plant Foods Hum Nutr., 65(4), 339-349.

Tudorica, C. M., Kuri, V., \& Brennan, C. S. (2002). Nutritional and physicochemical characteristics of dietary fiber enriched pasta. Journal of Agricultural and Food Chemistry, 50, 347-356.

Wierser, H., \& Koelher, P. (2007). The biochemical basis of Celiac disease. Cereal Chem., 85(1), 1-13.

\section{Copyrights}

Copyright for this article is retained by the author(s), with first publication rights granted to the journal.

This is an open-access article distributed under the terms and conditions of the Creative Commons Attribution license (http://creativecommons.org/licenses/by/4.0/). 